\title{
Empowerment by Digital Media of People with Disabilities
}

\section{Three Dimensions of Support}

\author{
Christian Bühler ${ }^{1}$ and Bastian Pelka ${ }^{2}$ \\ ${ }^{1}$ TU Dortmund University -Rehabilitation Technology-, Dortmund, Germany \\ c.buehler@reha-technologie.de \\ ${ }^{2}$ Social Research Centre - Central Scientific Institute, Technische Universität Dortmund, \\ Dortmund, Germany \\ pelka@sfs-dortmund. de
}

\begin{abstract}
The paper differentiates three dimensions of access for eInclusion instruments: Firstly, digital media are understood as environments that offer multiple channels for interaction between persons with disabilities and their environment. This dimension is challenged by barriers that hinder people to use digital media. Peer support could be understood as a second dimension: Social media can empower people to act as social innovators and help people with disabilities. Barriers are identified in the effort that has to be done or in unsuitable ICT-applications. On a third dimension, the advantages of "space" are explored: Public internet access points can be understood as a "space" that offers ICT access, support for individual needs and competences, facilitated by specialized staff. The high costs, missing political backing and need for competences could be understood as main barriers here. The paper suggests to capitalize on social innovation approaches to design new support instruments for eInclusion.
\end{abstract}

Keywords: Digital Media, Social Media, Public Access Point, People with Disability, Empowerment, eInclusion, Telecentre.

\section{The Digital Society - Potentials and Barriers for People with Disabilities}

Computers are widely accepted as instruments for people with disabilities supporting their ADL (activities of daily living) tasks at home and at work. This is very much supported by the institutional support setting and accepted by people with disabilities. Digital media are entering the everyday life tasks of people with disabilities at two sides: Firstly, digital media are offering support for traditional offline tasks. Examples are digital devices that support communication or orientation. Secondly, with the ubiquity of digital media in every single social sub system (education, politics, economics, health etc), digital media establish a new access mode to societal offers and discourses [1]. The education system strongly builds on ICT mediated learning environments [2], political decision making is increasingly affected by online discourses 
and economic procedures are widely transferred into online booking, shopping and selling. This transfer of social routines into digital net-works is supporting the participation of people with disabilities, as certain restrictions are decreased. At the same time, new barriers (accessibility, demand for new competences etc) arise and are about to dig new cleavages between mainstream and disadvantaged persons. It is an information society challenge to shape these environments in a way that persons with disabilities can exercise their rights in the same way than other people [3]. Against this backdrop, this article discusses three access dimensions for instruments aiming at empowering disabled people to use digital media and participate in the digital society.

\section{Three Dimensions of Support}

\subsection{Networking Dimension: Social Media}

Besides pure information retrieval from the web and communication by means of telephones combined platforms create new options for information, communication, shared interests, expression of opinions, gaming, entertainment, business etc. Although there exist profound skepticism and criticism with regard to security and privacy of such platforms, they are well accepted and part of the daily lives of very many people. The published numbers of users of the most common networks underpin the widespread acceptance (e.g. Facebook is accessed by 1.19 billion active users every month as of September 30, 2013 [4]). In Germany for example 46\% of the people who go online maintain a profile in social networks, $89 \%$ of those on Facebook [5]. So, obviously for many people advantages of social networks outbalance the reservations. It is interesting to note that technical accessibility of social networks is still an issue which is not fully solved. An approach following the concept of universal design and computers [6] seems to be necessary. A particular problem occurs in Web 2.0 applications, where users create content which does often not address accessibility at all. In user generated content, frequently used media like pictures and videos remain inaccessible. In this respect ATAG $2.0^{1}$ Part B (candidate recommendation) introduces guidelines how to support authors to produce accessible content.

Generally incomplete accessibility in user generated content seems to be more accepted compared to accessibility problems of the platforms and content of the providers. Therefore, the accessibility of the platforms and its content need to follow WCAG $2.0^{2}$.

Unfortunately, further non-technical barriers can be observed for people with restrictions in cognition [7]. Among those barriers range financing combined with the living situation (e.g. in nursing homes), but also related to the content e.g. complexity, difficult language, orientation and navigation options, mass of information, etc. [7]. Part of the problems are obviously related to the online content: the used language is too difficult and not easy to read; controls are ambiguous and inconsistent; websites provide too much content and too many operation options at a time; advertisements

\footnotetext{
${ }^{1}$ http: / / www.w3.org/TR/ATAG2 0/\#part_b

2 http: / / www.w3 . org/TR/WCAG2 o /
} 
attract the users' focus; captchas, pop-ups, unexpected content change on the page, timed response requirements irritate and distract the users. Many of those problems can be avoided following WCAG 2.0. However, additional measures seem to be necessary. The use of easy to read, plain language are very relevant in this context, but also new ways of presenting the various options of platforms combine with online tutorials and online-help systems are required.

Another part of the problems is connected to the users' settings. As long as the problems with the content and operation are recognized a general hesitation to go online can be observed. Users miss appropriate support ("it is anyway too complicated") or are kept on special private platforms for smaller "safe" communities ("we need to protect against improper and offensive content and economic online traps"). Hence people with learning difficulties and people with cognition problems seem to some extend being excluded from the online development and the inherent potential. Thinking in inclusive terms, it is necessary to investigate, how this kind of exclusion can be overcome. Remaining technical barriers (WCAG 2.0, ATAG 2.0) need to be removed but also content related issues solved. Appropriate assistance, access through simplified/ individualized interfaces, increase of media competence through training and courses, online resources are some of the measures to further investigate. A combination of training in secure environments, online help and assistance in groups is one promising approach. On the other hand, the idea of simplification the interface to access mainstream platforms as in principle proposed in GPII $^{3}$ is very much needed.

\subsection{Peer Dimension: Peer Support Platforms}

Peer support is a principle employed as self-help mechanism in many areas especially in the disability field. It follows the motto of the European Disability Forum (EDF "Nothing about us without us") and constitutes a powerful instrument unlocking the valuable experience of the peers with high credibility. Of course a direct contact face to face is often desired and also supporting the peer support process. However, nowadays peer support is no longer limited to face to face situations but has already entered the Web with several resulting advantages: First of all it is not restricted to a local community and hence possible to reach many more peers with a request, in principle world-wide. So one can address many peers or in case of orphan diseases/ disabilities at least some of the few existing. Secondly, it makes particular sense in Web and technology related issues, such as software problems, accessibility requirements, use of assistive technology or services. Blogs, FAQ, Fora, groups, Wikis, example videos, special websites provide a lot of options and huge potential for online peer support. A very special form of peer support is based on crowd sourcing where voluntary contributions either very small or maybe bigger are combined with a very profound result. Very good examples in the area of disability are "Universal Subtitles" of subtitles, "Meldestelle Digitale Barrieren" ${ }^{5}$ handling access problems to digital

\footnotetext{
${ }^{3}$ www.gpii.net

${ }^{4}$ Subtitling with Universalsubtitles: http: / / universalsubtitlesorg . html

${ }^{5}$ Meldestelle für digitale Barrieren: http: / / www . meldestelle.di-ji.de
} 
media, "Wheelmap" 6 for documenting low barrier locations for wheelchair users, "Selfpedia"7 responding to individual requests, "Knoffit" ${ }^{8}$ [8] providing an online glossary. Many of those are mainly based on voluntary contributions, but also financed peer support. More informal peer information can be found within the social networks by direct contacts or search e.g. in groups or channels. A difficult issue for the many good ideas is the wide dissemination and the sustainability on the one hand and the quality of the service e.g. correctness, thematic coverage, response time on the other. It further needs to be combined in a synergetic way with existing more traditional services by the self-help communities and professional providers. It needs to be understood as a complement of service structures rather than a replacement. Of course restricted capacity leads to the question of the most effective and efficient way of spending the available resources or raise further ones.

\subsection{Organizational Dimension: Public Internet Access Points and the "Space" Concept}

Next to help found on networks or from peers, we can distinguish a third dimension of support for digital competences in actual existing "brick and mortar" welfare institutions (like senior residences, nurseries or community welfare centers). Among these, the possibilities and demands of the information society have been scrutinized during the recent years and several forms of actual offline support institutions for the online world have been developed. More and more public institutions (like libraries, cultural centres and youth clubs for example) and welfare organizations offer free IT infrastructure, internet access, courses and individual support for disadvantaged persons on their way to the digital society as part of their empowerment services. South American and Mediterranean countries have shown a strong movement towards founding special dedicated spaces for eInclusion: the "Telecentre", which is defining itself primarily as an eInclusion actor. In other countries, public internet access points are part of existing welfare institutions and foster eInclusion empowerment as one branch among other welfare services. Libraries for example have recently strongly adopted their role as mediators of digital skills throughout Europe. Both types - dedicated "telecentres" or public internet access points as parts of existing welfare institutions with a broad variety of offers - could be understood as a third dimension of support for eInclusion which is using "space" and "proximity" as means of a low threshold target group approach. "Proximity" in this context does not only refer to geographical proximity, but also includes Boschma's understanding of cognitive, organizational, social and institutional proximity as supporting ingredients of learning [9]. In this sense, telecentres combine different facets of proximity in order to style eInclusion offers that suit best for their specific target groups, acknowledging the high demand of a target group specific approach of eInclusion. The physical space of a

\footnotetext{
${ }^{6}$ Wheelmap: http: / / wheelmap.org/en/

${ }^{7}$ Selfpedia: http://sel fpedia.de

${ }^{8}$ Das Mitmach Wörterbuch: http: / /www. knoffit.de
} 
telecentre is therefore used as a means to establish proximity to persons that are not profiting from ICT mediated forms of proximity (cf chapter 2.2).

Rissola/Garrido estimate that there are "almost 250,000 eInclusion organizations in the EU27, or an average of one eInclusion organization for every 2,000 inhabitants" [10]. More than a quarter of these institutions $(25.8 \%$ of the public and $28.4 \%$ of the third sector funded institutions) are targeting individuals with physical disabilities $18.8 \%$ of the public and $24.1 \%$ of the third sector funded organizations are targeting individuals with mental disabilities ([10]: 59). These institutions, predominantly publicly funded, operate with mostly less than 10 employees and a budget of less than 100,000 EUR per year [10] - shaping the "physical" eInclusion support structure in Europe as widely spread, but consisting of small institutions. The individual public internet access point (may it be a dedicated telecentre or a branch of a library, cultural club or senior residence) can be distinguished by the support it offers and the proximity to its target group. A four level pattern can be developed [2] that is reflecting Boschma's five layers of proximity by referencing to geographical, social, organizational, cognitive and institutional proximity between telecentre and users:

\begin{tabular}{|l|l|}
\hline $\begin{array}{l}\text { Level 1: } \\
\text { On demand assistance }\end{array}$ & Passive role; the telecentre only reacts to user's demand of help. \\
\hline $\begin{array}{l}\text { Level 2: } \\
\text { Level 1+ Training }\end{array}$ & $\begin{array}{l}\text { Provider of digital literacy training, the telecentre can also look } \\
\text { for/attract the users and give a social orientation to his/her } \\
\text { intervention. }\end{array}$ \\
\hline $\begin{array}{l}\text { Level 3: } \\
\text { Level 2+ User empowerment }\end{array}$ & $\begin{array}{l}\text { Provider of social inclusion services, the telecentre promotes the } \\
\text { digital autonomy of the users and their achievement of personal } \\
\text { goals taking advantage of the many resources available at the } \\
\text { Information Society }\end{array}$ \\
\hline $\begin{array}{l}\text { Level 4: } \\
\text { Level 3+ Active participation in in } \\
\text { community }\end{array}$ & $\begin{array}{l}\text { Provider of community service-learning, the telecentre promotes the } \\
\text { critical use of ICT and the engagement of the users with their local } \\
\text { communities/social belonging groups through their active } \\
\text { participation of community/social projects. }\end{array}$ \\
\hline
\end{tabular}

Fig. 1. Telecentre - Four levels of telecentres

Ongoing research $[11,12,13]$ indicates that albeit public internet access centers are well spread in Europe, there is a need to raise the competences of their staff in addressing disadvantaged persons' digital needs adequately. It is difficult to estimate the number of persons working with end users in the field of eInclusion, but taking 250,000 organisations as a basis, it seems safe to argue that around 250,000-375,000 persons in the EU are working on digital competences of disadvantaged persons. Only tentative research has been done on the socio demographic characteristics of this field of employment ${ }^{9}$, but it seems to prevail a young, female and highly educated workforce with a high diversity of educational profiles. This staff can be regarded as

\footnotetext{
${ }^{9}$ Cf.: http: / /www.efacilitator.eu/wordpress/wp-zontent/uploads / 2010/12/VET4e-i_Multi-Country_Context_AnalysisDEF.pdf
} 
persons with high interest in social innovation and strong links between this person group and social innovators could be traced through different social entrepreneurship organizations. This staff is in need of constant training and issues such as means to initiate and sustain fundraising, certification of competences and a high crew change rate have to be tackled. Recent re-search and development activities are aiming at these issues by developing customized and certifiable curricula for telecentres' staff (see http://www.trans-efacilitator.eu). The aim of this ongoing research and development activities is to support and secure professionalization within this new arising working field in order to make it more efficient for end users and more attractive for staff working on eInclusion issues.

\section{Conclusion}

Support structures for digital empowerment and eInclusion show a broad variety of approaches - digital, social or institutional; but mostly have just recently started. The short overview provided in this paper illustrates the pioneer status of many approaches and challenges their impact and sustainability. Web 2.0 and interactive social networks seem to provide very good potential to increase participation. But they also create new threats. Inaccessible user generated content and complexity issues create problems. People with intellectual problems are not sufficiently supported in this context. More effort as well online as in offline settings is required. To some extent online peer support and crowd-sourcing can be of help. Research has to show which concepts work and how existing concepts of care for people with disabilities might be connected to the eInclusion question. Many activities in this field are driven by individuals or small organizations, while traditional welfare is organized within large institutions with long established practices and strong connections to policy. The eInclusion scene at the moment is catalyzed by "social innovations" - new social practices and/or social configurations that are aiming at providing better solutions for societal challenges [14], whose origins, rules, behavior patterns, economic underpinnings and sustainability are widely unknown. Actual research has to explain how social innovation works for empowerment of digitally disadvantaged persons, which mechanism work and how policy could use social innovation as a pillar of its eInclusion activities (e.g. the "Digital Agenda Flagship initiative" under the "Europe 2020" strategy). Again, research is only on tentative level by now. But some suggestions from the field of social innovation research include (cf. [15]): The micro layer of innovation - the individual innovator and the individual process of up taking something new - seems to be of important for the "success" of a social innovation. Social innovations seem to rather occur in a stream of small innovations that being introduced as one big new idea. The preparedness of society and its willingness to co-construct an innovation is for social innovations much more important than for technological innovations. Imitating social practices seems to be the heart chamber of social innovation. Seeing these preliminary findings of recent research on social innovation as a binding element of the three support dimensions of empowerment by digital media of people with disabilities, the role of innovative individuals and their networks for providing 
digital inclusion should be valued highly. To this extend, eInclusion instruments could profit from social innovation research results and scrutinize the process of bringing social ideas to practice. But in contrast to national innovation systems for technological innovations, there is no innovation supporting frame for social innovations. Crowd funding and social media based cooperation seem to fill a gap at the moment, but policy will have to design their role within the context of social innovation for digital inclusion. One way could be to include social entrepreneurs and a combination of "new" and "small" eInclusion approaches with the practice of "old" and "powerful" welfare organizations that are step by step discovering the field of digital inclusion.

Acknowledgement. This paper is partly based on findings produced in a EU LLP funded project ("Trans eFacilitator"): http://www.adam-europe.eu/ adam/project/view.htm?prj=9831\#.Uuo8_vuj93s and the project DiJi (Digital informiert - im Job integriert) funded by BMAS (German Federal Ministry of Labor and Social Affairs): http: / / di-ji.de

\section{References}

1. Paraguay, A.I.B.B.: eInclusion: Policies and Concepts Regarding Persons with Disabilities - Considerations about Brazil and Portugal. In: Stephanidis, C. (ed.) Universal Access in HCI, Part I, HCII 2011. LNCS, vol. 6765, pp. 507-516. Springer, Heidelberg (2011)

2. Kaletka, C., Pelka, B., Diaz, A., Rastrelli, M.: eScouts: Intergen-erational Learning in Blended Environments and Spaces (ILBES) for social inclusion. In: European Distance and eLearning network (EDEN) (Hrsg.), Conference, June 6-9. Book of abstracts, Porto (2012),

http: / /www. eden-online.org/system/files/

Annual_2012_Porto_BOA.pdf

3. United Nations: The Convention on the Rights of Persons with Disabilities, CRPD (2008), http: / / www . un. org/disabilities / default. asp? navid=13\&pid=150

4. Facebook 2013 (2013)

5. Busemann, K.: Wer nutzt das Social Web? Ergebnisse der ARD/ZDF-Onlinestudie 2013 in Media Perspektive 7-8/2013 Frankfurt am Main (2013), http: / /www.ard-zdf-onlinestudie.de/fileadmin/ Onlinestudie/PDF/Busemann.pdf

6. Bühler, C.: Universal Design - Computer. In: Stone, J., Blouin, M. (eds.) Center for International Rehabilitation Research Information and Exchange (CIRRIE): International Encyclopedia of Rehabilitation (2010),

http://cirrie.buffalo.edu/encyclopedia/en/article/146/

(Abruf: January 29, 2014)

7. Berger, A., et al.: Web 2.0 barrierefrei. Eine Studie zur Nutzung von Web 2.0 Anwendungen durch Menschen mit Behinderung. Aktion Mensch e.V. Online verfügbar unter, Bonn (2010),

http: / publikationen.aktion-mensch.de/

barrierefrei/Studie_Web_2.0.pdf 
8. Schaten, M., Lexis, M., Roentgen, U., Bühler, C., de Witte, L.: User Centered Design in Practice - Developing Software with/ for People with Cognitive and Intellectual Disabilities. In: Assistive Technology: From Research to Practice, AAATE 2013, pp. 815-822. IOS Press (2013)

9. Boschma, R.A.: Proximity and Innovation: A Critical Assessment. Regional Studies 39, 61-74 (2005)

10. Rissola, G., Garrido, M.: Survey on eInclusion Actors in the EU27 (2013), http: / / ftp.jrc.es/EuRdoc/JRC84429.pdf

11. Lohrmann, L.: Trans eFacilitator comparative report (2013), http: / /www. adam-europe.eu/prj/9831/prd/1/1/ 3. 6\%20Comparative\%20Report.pdf

12. Pelka, B., Kaletka, C.: eFacilitators: Functional Hybrids between ICT Teaching and Community Management. In: Deitmer, L., Gessler, M., Manning, S. (eds.) Proceedings of the ECER VETNET Conference 2012: Papers Presented for the VETNET Programme of ECER 2012 at Cádiz, September 18-21. EERA Network: 02. Vocational Education and Training (VETNET), Wissenschaftsforum Bildung und Gesellschaft e.V, Berlin (2012a),

http: //www. ecer-vetnet.wifo-gate.org, http://www.b.shuttle.de/wifo/vetnet/ecer12.htm, http://vetnet.mixxt.org/networks/files/file.111156

13. Pelka, B., Kaletka, C.: Blended Learning Spaces as a Social Innovation for Local Inclusion, Integration and Employability. In: EIRP Proceedings, vol. 7 (2012b),

http: / /www.proceedings . univ-danubius.ro/ index.php/eirp/article/view/1362/1308

14. Howaldt, J., Schwarz, M.: Social Innovation: Concepts, Research Fields and International Trends. In: Henning, K., Hees, F. (eds.) Studies for Innovation in a Modern Working Environment - International Monitoring, vol. 5, p. 2011. Eigenverlag, Aachen (2010), http: / /www.sfs-dort-mund.de/odb/Repository/Publication/ Doc\%5C1289\%5CIMO_Trendstudie_Howaldt_Schwarz_ englische_Version.pdf (June 9, 2011)

15. Howaldt, J., Kopp, R., Schwarz, M.: Social innovations as drivers of social change Tarde's disregarded contribution to social innovation theory building. Social Frontiers. The next edge of social innovation research (2014) 